\title{
Combating plagiarism
}

\author{
Accountability of coauthors for scientific misconduct, guest authorship and deliberate or negligent \\ citation plagiarism, highlight the need for accurate author contribution statements.
}

Almost one hundred years ago in 1912, in a gravel pit in the village of Piltdown, East Sussex, England, the fragments of a skull and jawbone belonging to an early human were found, providing a new link between ape and man - or so it seemed. Today, however, Piltdown is famed not for a magnificent scientific discovery, but for scientific misconduct that stunted research on human evolution for decades.

Eoanthropus dawsoni, or 'Dawson's dawn-man', named after Charles Dawson who presented the specimen to the scientific community, was only definitively proved to be fraud some 40 years later in 1953 when the remains were shown to consist of the skull of a medieval-age man, the 500-year-old jaw of an orangutan and the teeth of a chimpanzee. The identity of the Piltdown forger is still unclear. What is abundantly clear is the damage that resulted; the 'find' sent many researchers in wrong directions, and for nearly two decades genuine finds were ignored by many and hundreds of papers related to the fraud were written.

Although it is to be hoped that scientific misconduct, including plagiarism, remains a fringe activity, the motivations are obvious. If undetected, it is conceivable that even subtle forms of misconduct may benefit an offender's career, for example in getting their $\mathrm{PhD}$, securing a permanent faculty position or enhancing a grant proposal.

Many forms of plagiarism exist, but the goal is generally the same - to garner false or undue credit. Plagiarism sometimes involves reuse of another author's published work, but it is commonly thought that the most typical tool of the plagiarist is selfplagiarism: the reuse of substantial parts of an author's own published work, particularly without appropriate referencing, and less commonly, duplicate publication, in which the results are recycled in their entirety.

The peer-review process provides a net for catching offenders, but it cannot provide a fail-safe barrier. As a result, Nature Photonics is now starting to use the plagiarism-detection software CrossCheck ${ }^{1}$, which makes comparative checks between provided manuscripts and those previously published and in an existing database. Any manuscript that seems to show an abnormally high match will be immediately

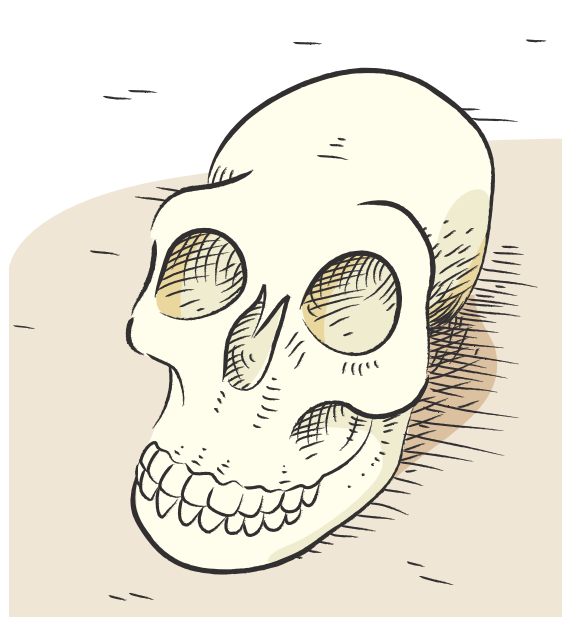

investigated. Unfortunately, plagiarism can also occur without verbatim duplication of words or data. And it is here that the lines between normal and acceptable activity and plagiarism become smeared, and the likelihood of detection and punitive repercussions is diminished.

Using another researcher's arguments and logic, even if the text is not identical, without due reference is intellectual plagiarism. This type of plagiarism can be subtle and as simple as not including a reference to a highly relevant previous paper. Citation-related plagiarism, whether it is intentional, or due to gross negligence, can give an untruthful impression of precedence, reassigning credit from the original discoverer to another person.

When reporting scientific messages, it is an author's responsibility to find and acknowledge the critically relevant literature, or at least to have endeavoured to do so with rigour. Failing this can result in falsely apportioned claims, albeit caused by negligence.

If plagiarism is suspected in research results published by us, it is our policy to conduct an immediate investigation and if deemed appropriate to contact the author's institute and funding agencies and consider a formal retraction of the paper $^{2}$. Although it is often the first authors who have historically borne the brunt of confirmed misconduct allegations, our editorial policies highlight the serious responsibilities of all coauthors: "submission to a Nature journal is taken

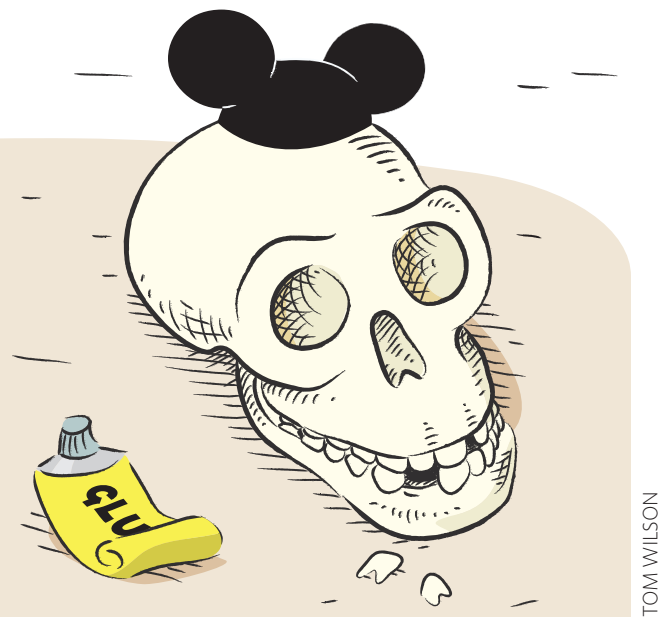

by the journal to mean that all the listed authors have agreed to the content" 3 . It is unreasonable to expect each author to be responsible for every aspect of the paper, but it is the responsibility of the corresponding author to manage the understanding that all authors are expected to have made reasonable attempts to check the findings submitted to a journal for publication ${ }^{3}$.

To help clarify author contributions, the current policy of Nature research journals is: "Authors are strongly encouraged to include a statement in the end notes to specify the actual contribution of each coauthor to the completed work" ${ }^{3}$. Such a statement serves at least two useful purposes: it is a statement that (should) clearly state each author's contribution, and hence to some extent also their responsibility in the case of misconduct, and it serves to discourage guest authorship - the unscrupulous practice of including authors for other than scientific reasons. We strongly recommend that all authors of papers submitted to Nature Photonics file such contributions for reasons of transparency, and as a model for good working practices for the communication of scientific research.

Published ideas, thoughts, concepts and results are the tangible essence of a scientist, and must be defended.

References

1. http://www.crossref.org/crosscheck.html

2. http://www.nature.com/authors/editorial_policies/plagiarism.html 3. http://www.nature.com/authors/editorial_policies/authorship.html 